\title{
Chlamydia trachomatis IgA Antibody Measurement
}

National Cancer Institute

\section{Source}

National Cancer Institute. Chlamydia trachomatis IgA Antibody Measurement. NCI

Thesaurus. Code C100464.

The determination of the amount of Chlamydia trachomatis IgA antibody present in a sample. 